\begin{tabular}{|c|c|}
\hline Title & Underground behavior of overwintering Tokyo daruma pond frogs in early spring \\
\hline Author(s) & Nakashima, Naohisa; Moriyama, Takumi; Motegi, Marina; Mori, A kira; Watabe, Keiji \\
\hline Citation & $\begin{array}{l}\text { Paddy and Water Environment, } 19,127-135 \\
\text { https://doi.org/10.1007/s10333-020-008245 }\end{array}$ \\
\hline Issue Date & 2021-01 \\
\hline DOC URL & http:/hdl. handle.net/2115/83739 \\
\hline Rights & $\begin{array}{l}\text { This is a post-peer-review, pre copy edit version of an article published in Paddy and W ater Environment. The final } \\
\text { authenticated version is avail able online at: https://doi.org/10.1007/\$10333-020-00824-5 }\end{array}$ \\
\hline Type & article (author version) \\
\hline File Information & PAWE_manuscript7_rev2_nohist.pdf \\
\hline
\end{tabular}

Instructions for use 


\section{Underground behavior of overwintering Tokyo daruma pond frogs in early spring}

\section{Abstract}

Although Tokyo daruma pond frogs (Pelophylax porosus porosus) were once commonly observed throughout paddy fields in Japan, their populations have recently declined. The mode by which frogs survive during the overwintering period is largely unknown. In this study, we observed the underground behavior of 12 free-living Tokyo daruma pond frogs that overwintered in paddy soil and a dry field by periodically excavating their overwintering positions from late March to early May. The mean overwintering depth of these frogs was 19.8 cm, with 10 having migrated toward the soil surface (mean depth: $\sim 8.6 \mathrm{~cm}$ ) by late March, and finally, all 11 live frogs migrated further upward close to the soil surface. In addition, males tended to emerge earlier in spring than females. One monitored frog in the paddy soil that migrated close to the soil surface died, presumably from plowing. Aside from the 12 study frogs, several other mutilated frog corpses were found in the paddies. This species starts migrating to the soil surface during the same period when human disturbances begin, making the frogs vulnerable to these disturbances during this period. Consequently, it is necessary to facilitate the emergence of frogs to protect them from human disturbances-e.g., by temporarily filling fields with water. 
Paddy fields provide habitats and breeding sites for many frog species. Frogs are considered biological indicators of ecosystem health because they thrive in diverse environments and are positioned in the middle nutrient stage of the food web as a food resource for other amphibians, reptiles, and birds (Mattoon 2001). The Tokyo daruma pond frog (Pelophylax porosus porosus) has been designated as an indicator species for biodiversity, and as useful for agriculture (Tanaka 2010). Historically, this species was found throughout paddies and their neighboring agricultural waterways. However, recently, the Tokyo daruma pond frog has experienced a substantial population decline; and was registered as a near-threatened species by the Ministry of the Environment, Japan in 2006 (Biodiversity Center, Ministry of the Environment 2006). Researchers have suggested that this population decrease is mainly the result of a decrease in preferred environmental factors due to the increased use of concrete for agricultural waterway construction (Osawa et al. 2003, 2006; Watabe 2014) and the shortening of the paddy flooding period (Murakami and Osawa 2008).

The protection of this species is a pressing problem. However, incomplete understanding of its life history hinders the development of potential conservation measures. Although knowledge around the breeding phase of the Tokyo daruma pond frog has been accumulated (for example, Fujioka and Lane 1997; Azuma and Takeuchi 1999; Tempaku et al. 2012; Yamamoto and Senga 2012), information on the life history of this species during the overwintering period is extremely limited. Only small numbers of previous studies have addressed overwintering in the Tokyo daruma pond frog or the closely related Nagoya daruma pond frog (Pelophylax porosus brevipodus). These studies focused on detecting hibernation sites, such as paddy fields and furrows (Niwa et al. 1999; Morita et al. 2001; Mizuno et al. 2007), an adjacent fallow paddy field (Tada et al. 2019), and drylands near their breeding paddies (Noda et al. 2019). However, although these studies required a great deal of research, the number of frogs found was not commensurate. This is because it is difficult to visually observe Tokyo daruma pond frogs during their overwintering period underground and thus also difficult to elucidate the overwintering ecology of this species (Kusano 2011). Noda et al. (2019) embedded passive integrated transponder (PIT) tags with a built-in passive radio frequency identifier (RFID) in the bodies of Tokyo daruma pond frogs to enable the successful detection of individuals that overwinter underground. Following the development of technology to determine a sufficient number of overwintering frogs, Nakashima et al. (2018) estimated the period when Tokyo daruma pond frogs emerge.

To the best of our knowledge, no study has assessed the behavior of the Tokyo daruma pond frog during the overwintering period. Nakashima and Moriyama (2018) reported that Tokyo daruma pond frogs begin to migrate to the soil surface in April when the soil temperature starts to rise. Furthermore, Nakashima et al. (2019) suggested that the abundant distribution of the Tokyo daruma pond frog is influenced by their hibernation sites that are being used as farmlands, such as paddy fields and drylands. Human disturbances in paddy fields, such as plowing and flooding, begin to occur from late March, and they may largely affect overwintering frogs in the soil. Therefore, it is necessary to explore frog migration to the soil surface during this period to guide conservation efforts for vulnerable and threatened species, such as the Tokyo daruma pond frog. Here, we defined this underground migration as a part of overwintering behavior and their emergence process in spring. Accordingly, this study investigated the underground behavior of Tokyo daruma pond frogs during the overwintering period using PIT tags. 


\section{Materials and methods}

\section{Research location}

The study sites are located in Kaminokawa Town, Kawachi, Tochigi Prefecture, in district K, where paddies and drylands are mixed, and district T, where paddies stretch uniformly across the district (Fig. 1). Districts $\mathrm{K}$ and $\mathrm{T}$ are $500 \mathrm{~m}$ apart. District $\mathrm{K}$ is an isolated unit of paddy fields surrounded by roads, rivers, and forest lands, consisting of nine paddies, three drylands, three greenhouse facilities, one waterway, and a forest land ( 2.4 ha in size) (Fig. 1). The nine district K paddies were managed by an organic farmer, whereas the three drylands were controlled by three different management entities. In the bare land ( $0.08 \mathrm{ha})$, crops were not planted and only periodic plowing was undertaken. There were greenhouses in district K; however, these facilities were excluded from the study sites owing to the difficulty in entering the greenhouses to capture and monitor frogs. One logger, used to measure ambient temperature (Satoshoji Corporation, MHB-382SD, recorded every $10 \mathrm{~min}$ ), was installed in district $\mathrm{K}$ in an instrument shelter $\sim 1.5 \mathrm{~m}$ aboveground.

District $\mathrm{T}$ consists of a unit of paddy fields ( 1.3 ha) surrounded by a paved road and large and small concrete trapezoidal drainage ditches (Fig. 1). The large ditch is approximately $4.0 \mathrm{~m}$ wide and $1.5 \mathrm{~m}$ deep, and the small ditch is approximately $1.6 \mathrm{~m}$ wide and $0.6 \mathrm{~m}$ deep. District $\mathrm{T}$ included six paddies and one dryland. The six paddies were cultivated by two management entities. T3 was an abandoned paddy and was therefore excluded from the target area.

\section{PIT tagging methods}

Prior to this study, wild Tokyo daruma pond frogs were captured using either a shrimp net with a $1.2 \mathrm{~m}$ handle or by hand, and then inserted with PIT tags (Biomark, BIO12B, length: $12.5 \mathrm{~mm}$, diameter: $2.1 \mathrm{~mm}$, weight: $0.1 \mathrm{~g}$ ) in the field, and immediately released at the site of capture by following the method of Noda et al. (2019). To avoid negative effects on survival or behavior, the PIT tags were inserted into the frogs with a snout-vent length (SVL) of $\geq 40 \mathrm{~mm}$ (Pyke 2005). However, just prior to the overwintering period, the PIT tags were also inserted into frogs with an SVL of 35-40 mm because several captured frogs were smaller than $40 \mathrm{~mm}$ long. The tags were inserted from May to October 2017 in both districts. In district T, the capture and tagging areas were extended westward and partially southward, as shown in Fig. 1 (fields surrounded by a thick black line), to improve capture effectiveness. The sex of each frog was determined by referring to the observations of Serizawa and Serizawa (1990), by the existence of a vocal sac, which indicated males, or SVL of $>50 \mathrm{~mm}$, which indicated females. The PIT tags were inserted into 111 frogs in district K (mean SVL $=54.6 \pm 7.2 \mathrm{~mm}$ for males, $66.4 \pm 8.4 \mathrm{~mm}$ for females) and 211 frogs in district $\mathrm{T}$ (mean SVL $=48.2 \pm 8.0 \mathrm{~mm}$ for males, and $61.8 \pm 11.4$ $\mathrm{mm}$ for females).

Overwintering frogs were searched in all farmlands in district $\mathrm{K}$ and farmlands on the eastside in district T from November 2017 to January 2018. The survey was conducted for 7-9 days in each district. A portable antenna (Biomark, BP Portable Antenna, weight: $1.6 \mathrm{~kg}$ ) and a reader (Biomark, HPR-Plus, weight: 1.2 $\mathrm{kg}$ ) were used to search for frogs by walking through paddies, drylands, waterways, and forestlands at a speed of $1 \mathrm{~m} / \mathrm{s}$. 


\section{Excavation methods}

After detecting the PIT tag signal, the detection spot was excavated to check the survival of the tagged frog and measure the depth of the spot, at which it overwintered. Eleven overwintering frogs distributed evenly across each farmland were selected (three from the drylands in district $\mathrm{K}$ and eight from the paddies in district T) (Fig. 2). The targeted frogs were regularly excavated to measure the overwintering depth and observe their underground behavior. An overwintering frog F315 was found for the first time on April 1, 2018 in the bare land in district K (Fig. 2). After excavating the soil to check its survival, it was confirmed to be physiologically inactive and overwintering at a depth similar to those of other overwintering frogs; therefore, this frog was included as a study subject.

First, a flag was planted to mark the detection sites by the portable antenna. The sites were then excavated using a handheld reader (Trovan, ARE H5) to check the planar location. The exact sites where the overwintering frogs were assumed to be submerged were excavated by quietly digging the soil mass with a trowel in a piecemeal fashion until the depth where a part of the target frogs' body could be seen. The overwintering depth was measured with a bamboo scale from the determined soil surface to the top of the body of the frogs (Fig. 3). Thereafter, the turned soil was quickly and silently replaced, and pressure was slowly applied downward to strengthen the soil and restore soil hardness close to that before excavation. When replacing the soil, we covered the frogs with a large and flat soil mass (i.e., like placing a lid on top of its body) to protect the frogs from the pressure applied to harden the soil. Leveling was performed to allow changes in the overwintering depth to be compared over time despite the changes in the soil surface due to plowing. Briefly, a control point was positioned near the research farmland to determine the height of the level position from the control point in each measurement (Fig. 3a). The height of the ground level near the excavation site was then measured through leveling (Fig. 3b). The overwintering depth of each study frog was measured relative to the "leveled" soil surface using a bamboo scale (Fig. 3c). The defined control point was fixed by driving timber piles deep into the exteriors of the paddy fields, such as furrows and banks. The first set of excavations was conducted at the same time when the PIT tags were detected to determine survival and overwintering depths (initial overwintering depths), from November 2017 to January 2018 (Noda et al. 2019). The subsequent eight tracking excavations were conducted during the daytime on March 27; April 5, 9, 12, 17, 21, and 27; and May 2, 2018. Moreover, from March 8 to May 31, 2018, the research farmlands were surveyed every day, including days when excavations were not conducted, to check the portable antennae's reactions from the ground surface. We defined the frog as emerging when the portable antennae could no longer detect the PIT tags around the points where they were previously detectable.

\section{Underground behavior}

\section{Results}

We found 15 overwintering frogs in district $K$ at an average overwintering depth of $16.4 \pm 4.1 \mathrm{~cm}$ and 43 overwintering frogs in district $\mathrm{T}$ at an average overwintering depth of $18.5 \pm 5.0 \mathrm{~cm}$. Information on the 12 study frogs, their initial hibernation depths, and the number of days until their emergence from the ground is shown in Table 1. Each frog presented in Table 1 was assigned an individual ID based on its sex and the last three digits of its PIT tag number. The overwintering depth of three frogs in district K was measured in January 2018 (that of 

discovered in the bare land on April 1, 2018 was $20.2 \mathrm{~cm}$ at the time of discovery. Likewise, the overwintering depths of eight frogs in district T, measured in January 2018, ranged from 14.0 to $32.0 \mathrm{~cm}$, with a mean ( \pm SD) depth of $19.9 \pm 6.6 \mathrm{~cm}$. The mean overwintering depth of the 12 selected frogs was $\sim 19.8 \mathrm{~cm}$, with 10 of the frogs having migrated toward the soil surface (mean depth: $\sim 8.6 \mathrm{~cm}$ ) by late March.

The underground behaviors of the overwintering frogs in early spring are shown in Fig. 4. All frogs had migrated upward to near the soil surface, i.e., to depths shallower than those initially observed. M937 and M948 were found to overwinter in the drylands in district $\mathrm{K}$ and migrated upward to a depth of $2.3 \mathrm{~cm}$ (M937) and 10.4 cm (M948) from the soil surface, respectively, on March 27 (excluding the data of the missing frog, M956, and the additional frog, F315, found in April). The overwintering depth of the frogs in district T, as observed in March 27, was $7.8 \pm 3.1 \mathrm{~cm}$ (excluding the data of the missing frog). Many of the frogs that migrated upward had closed both their upper and lower eyelids, and they were physiologically inactive. All study frogs were found to move almost vertically from the initial overwintering spot. Eleven frogs took an average of 11.1 days to emerge since the first excavation date, March 27, 2018 (except for one newly added frog). The newly added frog, F315, migrated slowly to a depth of $21.0 \mathrm{~cm}$ on April 5, $19.0 \mathrm{~cm}$ on April 12, and $18.5 \mathrm{~cm}$ on April 21. The frog remained at this depth until April 27, and then it ascended sharply to $12.7 \mathrm{~cm}$. Such a behavior was not observed in other frogs that overwintered in the same or neighboring farmlands, because they had already migrated upward since the initial observation. We could not identify the cause for the delayed migration of this frog compared with the other study frogs. Nonetheless, this frog remained at a depth of 12.7 to $11.0 \mathrm{~cm}$ for eight days before emerging on May 4, which was similar to the observed behaviors of the other frogs. These results indicated that members of this species tend to migrate upward from the overwintering position to positions near the soil surface.

\section{Modes of underground movement}

The individuals presented in Fig. 2 and Fig. 4 are the same, and the combination of these two figures

160 allowed us to compare the distance that each target frog moved. Because periodic cultivation in the bare land in district K was undertaken on March 27, we were unable to conduct a survey on the following day, March 28. Therefore, although M937 was confirmed to have already emerged on March 29 (Fig. 4c), the actual day of emergence could not be accurately determined.

F072 and F012 that overwintered in T1 exhibited similar underground movements (Fig. 4a). In T5 and T6, three Tokyo daruma pond frogs (U122, F103, and F149) exhibited similar underground movements (Fig. 4b). Two of them also submerged from the elevated sites between March 27 and April 5, 2018 (Fig. 4b). The minimum daily ambient temperature exceeded $0^{\circ} \mathrm{C}$ for the first time on March 17 and continued to decrease to around $0^{\circ} \mathrm{C}$ until early April (Fig. 5). However, we could not determine any relationship between the two frogs that migrated downward in the soil again and the changes in temperature.

The number of days until emergence were counted to discuss the different movements between sexes of Tokyo daruma pond frogs, as shown in Table 1. Counting was started on March 17 because on that day the minimum daily temperature exceeded $0^{\circ} \mathrm{C}$ for the first time (Fig. 5). We were unable to determine the sex of 
an average of 18 and 35 days to emerge, respectively. Males emerged on an average $\sim 17$ days before females ( $\mathrm{p}$ $<0.05$, Welch-test).

\section{Influence of plowing}

Paddy fields T1 and T2 were managed by the same management entity and plowing was conducted on March 29, 2018. The four study frogs in these fields were all confirmed to be alive and had migrated upward in the soil by March 27. Leveling and excavations on April 5 after plowing revealed that three of the four frogs were alive. The lower body of the fourth, dead frog was compressed and crushed. Generally, plowing depth for paddies is 10 $\mathrm{cm}$. The dead frog had migrated to $\sim 5.2 \mathrm{~cm}$ below the surface before plowing. The other three surviving frogs had migrated to depths of $10 \mathrm{~cm}$ or deeper (Fig. 4a).

\section{Discussion}

186 We refound 15 overwintering frogs of the 111 frogs inserted with PIT tags in district K and 43 overwintering frogs of the 211 captured and marked frogs in district T; i.e., the rate of refinding the frogs were $~ 13.5 \%$ and $\sim 20.4 \%$, respectively. During the wintering survey, we observed 61 dropped tags ( $\sim 55.0 \%)$ and 6 rotting corpses ( 5.4\%) in district $\mathrm{K}$, and 19 dropped tags ( 9.0\%) and 6 decayed frogs ( 2.8\%) in district $\mathrm{T}$. The loss of other tags can be partially attributed to individuals leaving the survey area due to predation or migration and failure to detect underground tags. The latter was mainly a consequence of bumpy surfaces in paddy fields resulting in a narrower tag reception range than the range of 20-25 cm reported by Noda et al. (2019). However, the overall rate of refinding the frogs using the PIT tag method, including dropped tags, was high enough to consider it an efficient method for detecting overwintering frogs, especially in fields with a simple structure without a ditch such as those in district $\mathrm{K}(\sim 73.9 \%)$.

All frogs were confirmed to have migrated upward from the original overwintering position to near the soil surface before emerging (Fig. 4). This pattern was observed irrespective of differences in overwintering locations, drylands, or paddies. They migrated upward and spent 11 days on an average at a shallower position than the original hibernation depth. We could not determine the factors responsible for the behaviors in the soil based solely on the data from this study. However, considering that a) most frogs cannot survive below the frost line, b) they determine their overwintering depth in relation to the frost line (Breckenridge and Tester 1961; van Gelder et al. 1986; Tattersall and Ultsch 2008), and c) the predominant factor for awakening overwintering frogs is believed to be an increase in temperature (Duellman and Trueb 1986), we surmise with high reliability that migration in soil is associated with temperature change. The minimum daily temperature started exceeding $0^{\circ} \mathrm{C}$ on March 17 in the research districts (Fig. 5). These data imply that these frogs began migrating in the middle of March or later.

The number of days until the frogs emerged tended to differ between sexes, whereby males emerged earlier than females. For Pool frogs (Pelophylax lessonae) and Edible frogs (Pelophylax kl. esculentus), both belonging to the same genus as Tokyo daruma pond frogs, the males of both species arrived to breeding sites one week before the females (Holenweg and Reyer 2000). It is known that male frogs hibernate close to their breeding sites to arrive at the breeding site early (Zweifel 1989; Pilliod et al. 2002; Regosin et al. 2003; Liang 2013). These findings suggest that males tended to start emerging earlier than females at the end of the 
hibernation period as well as pre-breeding. Further investigations are needed to reveal the factors that cause these differences in underground behavior between the sexes.

In this study, emergence was defined as the day when a tag signal was no longer detectable from the antenna records. However, there might be other reasons why tag signals could not be detected, e.g., predation of frogs and movement of frogs. As for predation, there was no evidence of any digging at the surface around

218 hibernation points during the survey, as observed when animals prey on burrowing frogs. On the other hand, in

219 the case of the Nagoya daruma pond frog, an individual may emerge, and then burrow again (Doi et al. 2010) in

220 the middle of winter. This movement is most likely to escape from sites with unfavorable low temperatures to

221 survive (Holenweg and Reyer 2000). However, because this study began in late March, when temperature starts

222 to raise, the frequent movement was unlikely. Therefore, the definition of emergence in this study is sufficient to

223 provide data to show when the frogs end their overwintering.

224 Paddies in the research districts experience human disturbances, such as plowing, from late March.

225 Therefore, the period in which this species starts migrating to the soil surface coincides with the period when

226 human disturbances start to occur. In the paddies, the frogs that remained at $10 \mathrm{~cm}$ or deeper prior to emergence

227 survived, whereas those that migrated to shallower depths died from their lower body being crushed, presumably

228 as a result of plowing. We also found several other frog corpses in the paddy fields (e.g., frogs that were crushed

229 to death by a cultivator). No corpses were found with these characteristics in the drylands, in which plowing did

230 not take place in early spring. Because the mean overwintering depth of this species in paddies in the research

231 districts was deep ( $18.5 \mathrm{~cm})$, it can be assumed that plowing would not have considerable influence on frog

232 survival, if the frogs emerge quickly. However, our study revealed that the frogs migrated toward the soil

233 surface; therefore, the survival of immovable frogs overwintering in soil is affected by human disturbances.

234 The fact that Tokyo daruma pond frogs migrated towards the soil surface suggests that conservation

235 measures are required to facilitate their emergence in paddy fields during this period. Nakashima et al. (2018)

236 suggested that because underground frogs might emerge in accordance with rising soil water content, pools

237 farmlands temporarily with water might facilitate frog emergence. In the districts, paddling was started around

238 the end of April. During this period, a large number of Tokyo daruma pond frogs approached the soil surface.

239 Therefore, we recommend spilling water over the surface of paddies several days before paddling. In contrast,

240 drylands do not require the same precautions to preserve frogs because they have negligible human disturbance,

241 as observed during the study period. However, further investigation of the microenvironment factors regulating

242 their underground behaviors is required. Moreover, there was no significant difference in the emergence

243 behaviors of frogs between the different fields in this study. This suggests that the same kind of measures should

244 be applied at the same time for regional conservation. In recent years, advances in remote sensing technology

245 have enabled soil moisture content measurements (e.g., by satellite analysis and using unmanned aerial vehicle).

246 This ecological knowledge should be applied to environmental conservation plans at a large scale in farming.

247 In this study, we periodically excavated overwintering frogs and observed their underground migrations.

248 Our research revealed that Tokyo daruma pond frogs migrated upward to near the soil surface from their initial

249 overwintering position in early spring. In this study, we could not identify the environmental factors that

250 regulated their movements or caused some frogs to re-submerge following surface emergence. The underground

251 behaviors of Tokyo daruma pond frogs in early spring as well as their hibernation site conditions are directly 
related to issues with the conservation policies of this species. Therefore, detailed investigations are required to

253 elucidate the environmental factors that regulate the migration and emergence of this species after overwintering 254 underground.

255 


\section{References}

Azuma A, Takeuchi K (1999) Relationships between population density of frogs and environmental conditions in Yatsu-habitat. J Jpn Inst Landsc Arch 62:573-576. doi: 10.5632/jila.62.573 [in Japanese]

Biodiversity Center of Japan, Ministry of the Environment, Japan (2006) Revised red list reptile and amphibian: Available via online. https://ikilog.biodic.go.jp/Rdb/booklist of subordinate document. [in Japanese] Accessed 1 Oct 2019

Breckenridge WJ, Tester JR (1961) Growth, local movements and hibernation of the Manitoba toad, Bufo hemiophrys. Ecology 42:637-646. doi: 10.2307/1933495

Doi T, Nozaki N, Yoshida M, Kanou C, Fukuda Y (2010) Observation hibernation of daruma pond frog, Rana porosa brevipoda reared in outdoor tanks. Hyogo Freshwater Biol 61/62:189-194 [in Japanese]

Duellman WE, Trueb L (eds) (1986) Biology of amphibians. McGraw-Hill, USA

Fujioka M, Lane SJ (1997) The impact of changing irrigation practices in rice field a frog population of the Kanto Plain, Central Japan. Ecol Res 12:101-108. doi: 10.1007/BF02523615 [in Japanese]

van Gelder JJ, Olders JHJ, Bosch JWG, and Starmans PW (1986) Behavior and body temperature of hibernating common toads Bufo bufo. Holarctic Ecol 9:225-228. doi: 10.1111/j.1600-0587.1986.tb01212.x

Holenweg AK, Reyer HU (2000) Hibernation behavior of Rana lessonae and R. esculenta in their natural habitat. Oecologia 123:41-47. doi: 10.1007/s004420050987

Kusano T (2011) Ryouseirui no seitai kenkyuu ryouseirui no hanshoku idou wo rei to shite (Ecological study on amphibians using migration for breeding as an example). In: Matsui M (ed) The directions in batrachology. Shokabo Co Ltd, Japan, p 27 [in Japanese]

Liang TC (2013) Movements and habitat use of yosemite toads (Anaxyrus (formerly Bufo) canorus) in the Sierra national forest, California. J Herpetol 47:555-564. doi: 10.1670/12-054

Mattoon A (2001) Deciphering amphibian declines, pp 63-82 In: Brown LR, Flavin C French H (eds) A Worldwatch Institute Report on Progress Toward a Sustainable Society. W W Norton \& Co Inc, USA

Mizuno A, Okubo, K, Sawahata T (2007) Nagano-ken Ina-bonchi ni okeru daruma gaeru no tomin jokyo. Ann Meet Ecol Soc Jpn P2-235 [in Japanese]

Morita T, Kameyama T, Okada S (2001) Notes on hibernation of a Japanese pond frog, Rana porosa brevipoda. Bull Herpetol Soc Jpn 2001:46-47. doi.org/10.14880/hrghsj1999.2001.28 [in Japanese]

Murakami H, Osawa S (2008) Effects of paddy rice cultivation type on the distribution of Rana nigromaculata and Fejervarya limnocharis. Jpn J Conserv Ecol 13:187-198. doi: 10.18960/hozen.13.2_187 [in Japanese]

Nakashima N, Moriyama T (2019) Developing the distribution model of Tokyo daruma pond frogs considering field's conditions. Proceeding of the 31th year of the Heisei period Conference of JSIDRE:788-789 [in Japanese]

Nakashima N, Noda K, Moriyama T, Mori A, Watabe K, Tamura T (2018) A case study of the conditions for crawling out by Tokyo Daruma pond frogs hibernating in the cultivated fields. JSIDRE 86:225-234. doi: 10.11408/jsidre.86.I_225 [in Japanese]

Niwa N, Aoyama S, Doi T, Ohbuchi M, Nomura K (1999) Kobe-shi ni okeru daruma gaeru no seisoku jokyo ni t 
suite. Hyogo Freshwater Biology 50:37-43 [in Japanese]

Noda K, Nakashima N, Moriyama T, Mori A, Watabe K, Tamura T (2019) Development of methods to detect hibernation sites of Tokyo Daruma pond frog (Pelophylax porosus porosus) using the PIT Tag system. Ecol Civ Eng 22: 165-173. doi.org/10.3825/ece.22.165 [in Japanese]

Osawa S, Katano J, Katsuno T (2003) Inhabitation of the Pond frog Rana porosa porosa in a ditch on the rural landscape of spreading paddy fields characterized by dispersed settlement. J Rural Plann Assoc 22:7-12. doi: 10.2750/arp.22.22-suppl_7 [in Japanese]

Osawa S, Kuroda T, Katsuno T (2006) The change of vegetation, fauna of frogs and mousse as small animals, on different management level in step-like paddy fields. J Jpn Inst Landsc Arch 69:565-570. doi: 10.5632/jila.69.565 [in Japanese]

Pilliod SD, Peterson CR, Ritson PI (2002) Seasonal migration of Columbia spotted frogs (Rana luteiventris) among complementary resources in a high mountain basin. Can J Zool 80:1849-1862. doi: 10.1139/z02-175

Pyke G (2005) The use of PIT tags in capture-recapture studies of frogs: A filed evaluation. Herpetol Rev 36:281-285.

Regosin JV, Windmiller BS, Michael RJ (2003) Terrestrial habitat use and winter densities of the Wood frog (Rana sylvatica). J Herpetol 37: 390-394. doi: 10.1670/0022-1511(2003)037[0390:THUAWD]2.0.CO;2

Serizawa T, Serizawa S (1990) Reproductive traits of the rana nigromaculata-porosa complex in japan III. Sexual maturation and egg-laying of Rana porosa porosa. Jpn J Herpetol 13:70-79. doi: 10.5358/hsj1972.13.3_70 [in Japanese]

Tada M, Ito K, Saito M, Mori Y, Fukumasu J, Nakata K (2019) Wintering site environment for the Nagoya daruma pond frog (Pelophylax porosus brevipodus) in Kurashiki, Okayama Prefecture, Western Japan. JSIDRE 87:179-187. doi.org/10.11408/jsidre.87.I_179 [in Japanse]

Tanaka K (2010) Nougyou ni yuuyou na seibutsu tayosei no shihyou Nourin suisan shou purojekuto kenkyuu no gaiyou (Indicators for biodiversity that are useful for agriculture: An overview of the research project of the Ministry of Agriculture, Forestry and Fisheries). Shokubutsu Bou Eki (Plant Protect 64:600-604 [in Japanese]

Tempaku M, Osawa S, Katsuno T (2012) The faunistic composition of frogs corresponding to the rice fields with various conditions in Noubi plains. J Jpn Inst Landsc Arch 75:415-418. doi: 10.5632/jila.75.415 [in Japanese]

Tattersall GJ, Ultsch GR (2008) Physiological ecology of aquatic overwintering in ranid frogs. Biol Rev 83:119-140. doi: 10.1111/j.1469-185X.2008.00035.X

Watabe K (2014) Restriction of frog migration by constructing agricultural concrete channels and conservation of frog populations. Bull Natl Inst Rural Eng 53:63-104. doi: 10.24514/00002260 [in Japanese]

Yamamoto Y, Senga Y (2012) The distribution of the Tokyo Daruma pond frog, Rana porosa porosa, and its habitat status in paddy fields fragmented by urbanization. Jpn J Conserv Ecol 17:175-184. doi: 10.18960/hozen.17.2_175 [in Japanese]

Zweifel RG (1989) Calling by the frog, Rana sylvatica, outside the breeding season. J Herpetol 23:185-186. doi: $10.2307 / 1564030$ 


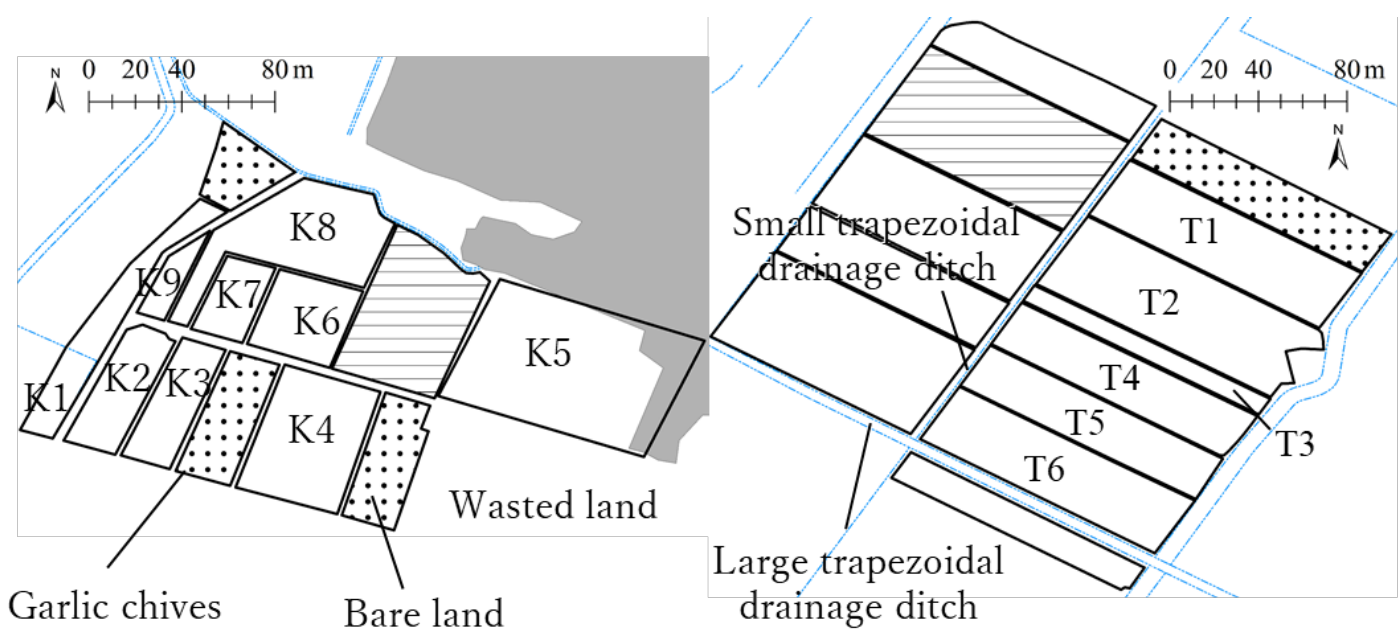

Fig. 1 Paddy field numbers and their modes of usage within paddy field units in districts $\mathrm{K}$ and $\mathrm{T}$ in

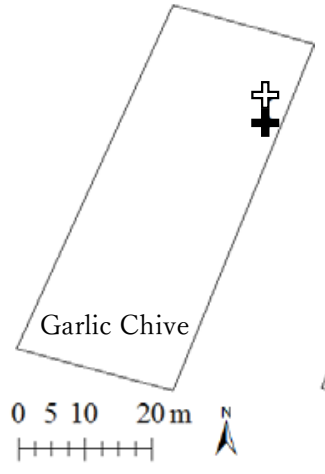

343

344

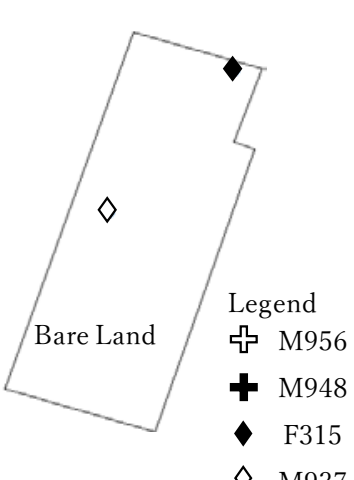

$\diamond$ M937

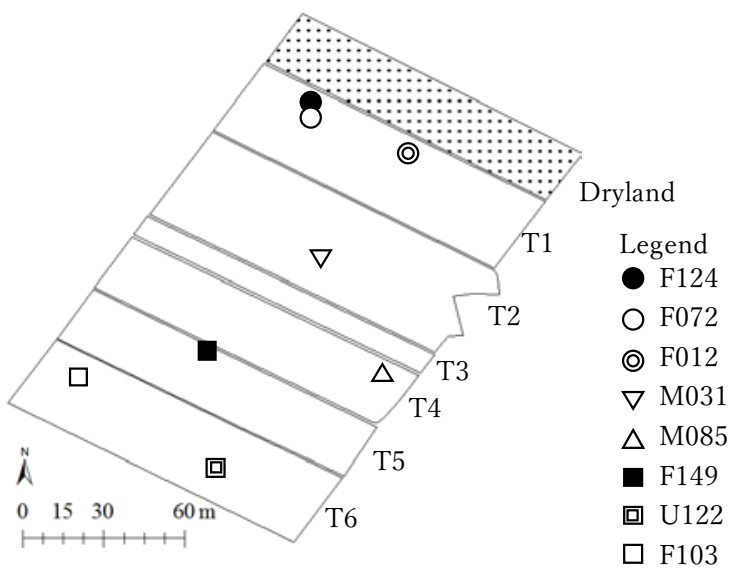

Fig. 2 Distribution of live overwintering Tokyo daruma pond frogs (Pelophylax porosus porosus) in districts K (left) and T (right). Each mark represents points of submerged overwintering frogs. Numbers beside each mark represent the PIT tag numbers of frogs. 


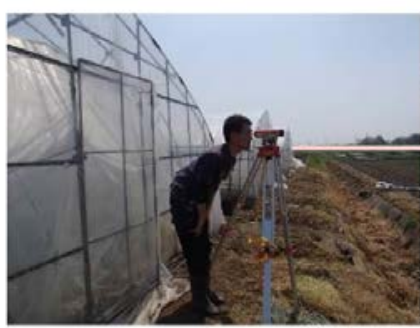

(a)

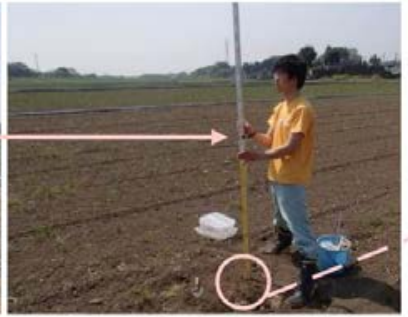

(b)

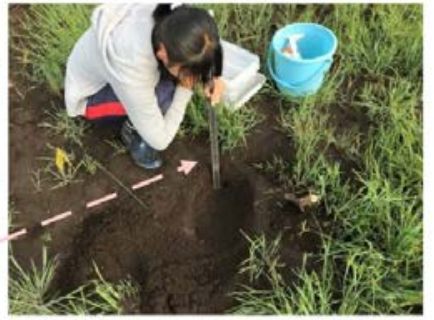

(c)

348

349 Fig. 3 Methods to measure the underground depth of frogs. (a) The control point was used to determine the

350 height of the level for each observation. (b) The height of the soil surface was determined based on the level, e.g., 351 for excavation spots in which frogs are submerged. (c) The depth at which the overwintering frogs were found 352 was measured from the soil surface using a bamboo scale. 

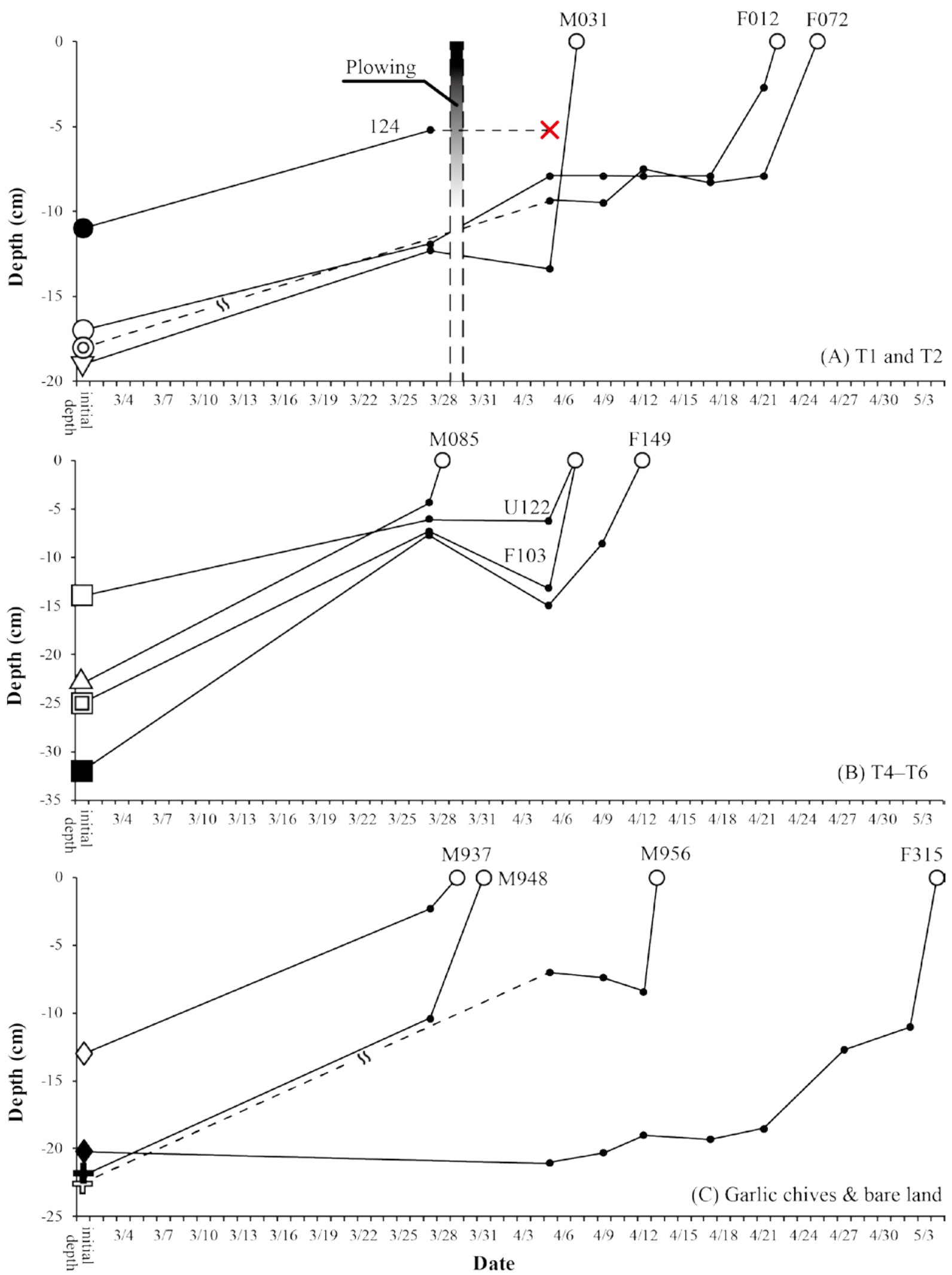

Fig. 4 Underground behavior of overwintering Tokyo daruma pond frogs (Pelophylax porosus porosus).

356 Behavior of overwintering frogs in district sites T1 and T2 (see Fig. 1) (a), in district sites T4-T6 (b), and in garlic chives and bare land (c). Plowing was performed by the same farmer in T1 and T2 on March 29, 2018. The frog that moved upward to the shallow site was crushed to death before or after plowing and was confirmed 
dead on April 5 (indicated by the X mark), the second observation date. Dots represent the excavation dates and soil depths, and open circles represent the dates when the frogs were confirmed to have emerged. Each mark at the start point represents an individual frog, which corresponds to the data in Fig. 2. Data were missing for frogs (F072 and M956) on March 27.

363

364

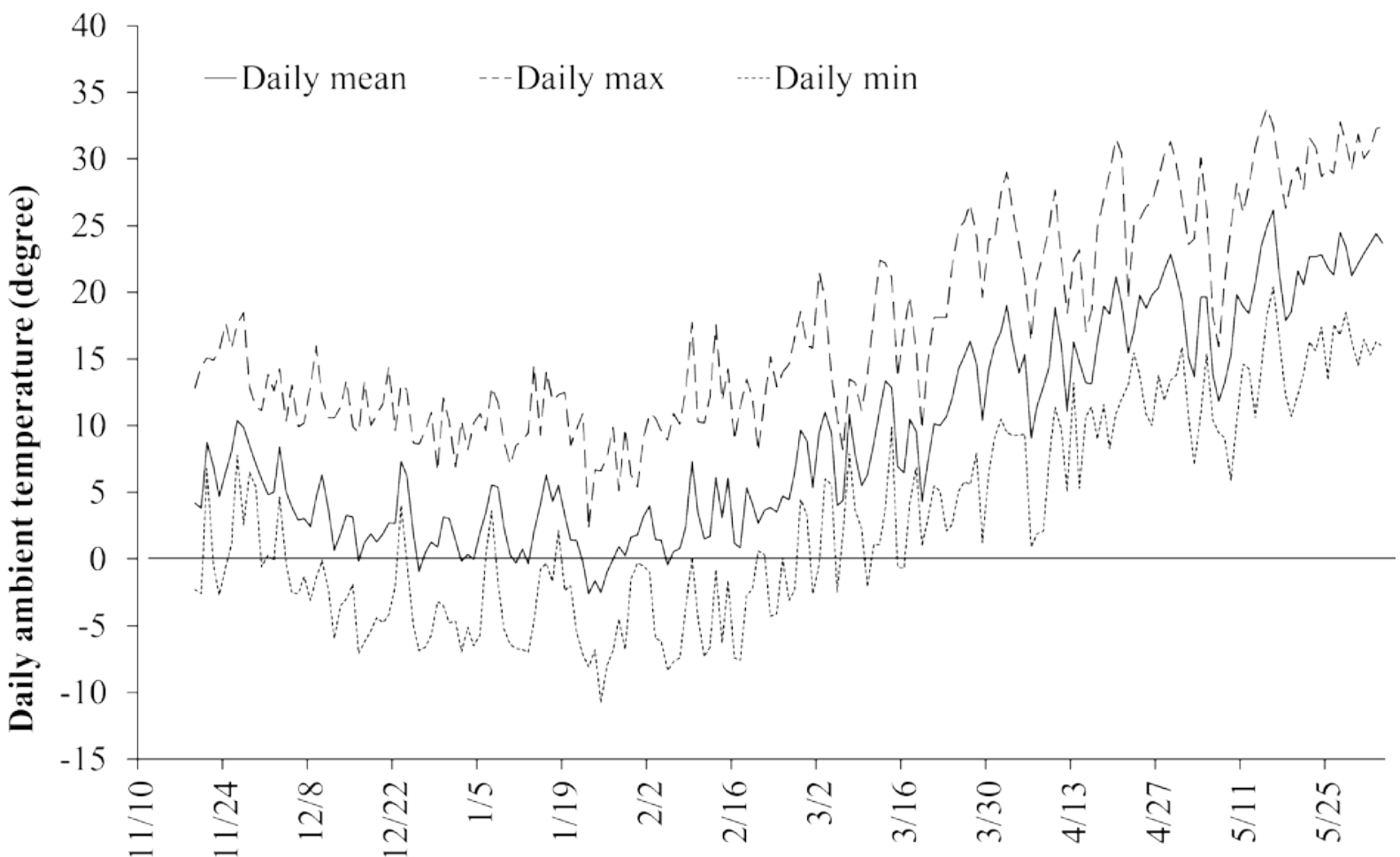

Fig. 5 Ambient temperature variations in the research districts. District K, where the ambient temperature was measured, is in a hollow in the mountains. Thus, ambient temperature fluctuation was less than that in the flatlands. The minimum daily temperature exceeded $0^{\circ} \mathrm{C}$ for the first time in March 17, 2018, but continued to show a sudden decrease to around $0^{\circ} \mathrm{C}$ until April 6, 2018. 